\title{
Psychology's contemporary and all-time notables: Student, faculty, and chairperson viewpoints
}

\author{
STEPHEN F. DAVIS, ROGER L. THOMAS, and MELANIE S. WEAVER \\ Emporia State University, Emporia, Kansas 66801
}

\begin{abstract}
Chairpersons of graduate psychology departments were surveyed to determine which psychologists this group viewed as having achieved contemporary and all-time importance. The results of this survey were compared with similar data gathered in 1966 . To provide a basis for additional comparisons, all psychology students and faculty at a regional midwestern university were administered similar surveys.
\end{abstract}

Schultz (1981) indicates that "two approaches can be taken to explain how a science like psychology develops: the personalistic or 'Great Man' theory and the naturalistic or 'Zeitgeist' theory." Throughout the years, the relative merits of these two theories have been hotly contested (see Schultz, 1975). However, the intensity of this debate appears to have subsided considerably in recent years. In fact, two recent texts (Leahey, 1980; Sahakian, 1981) dealing with the history of psychology do not even mention it. That this debate is becoming much less pronounced might possibly be linked to the current nature of theorizing in psychology. Grand, encompassing theories, such as those proposed by Hull (1943, 1952), Spence (1960), Thorndike (1931), and Tolman (1932), have given way to a new wave of minitheories (see Schultz, 1975). Likewise, the number of divisions or specialties represented within the American Psychological Association has witnessed rapid growth and expansion in recent years. Psychology is truly becoming recognized as a multifaceted discipline.

Such trends toward diversification of speciality areas suggest that the number of psychologists whose names are recognizable across all aspects of the discipline may be dwindling. In 1966, a Southern Methodist University survey (Moore \& Seberhagen, Note 1) was sent to chairpersons of American and Canadian graduate psychology programs. The purpose of this survey was to determine who these individuals viewed as the most important contemporary and all-time psychologists. The results of this 1966 survey are shown in Table 1.

These 15-year-old data prompted several questions: How lasting has the popularity or perceived importance of those listed in 1966 been (i.e., how would a similar sample respond in 1981)? How would the responses from a single institution compare with those of a national sample? How well do student opinions compare

Portions of this paper were presented at the annual meeting of the Southern Society for Philosophy and Psychology, Fort Worth, Texas, 1982.
Table 1

Most Important Contemporary and All-Time Psychologists According to Graduate Psychology Department Chairpersons-1966

\begin{tabular}{lcllc}
\hline Contemporary & Points & \multicolumn{1}{c}{ All Time } & Points \\
\hline 1. B. F. Skinner & 688 & 1. S. Freud & 668 \\
2. C. R. Rogers & 324 & 2. W. James & 400 \\
3. N. E. Miller & 311 & 3. W. Wundt & 329 \\
4. H. F. Harlow & 273 & 4. J. B. Watson & 328 \\
5. D. O. Hebb & 253 & 5. I. P. Pavlov & 287 \\
6. G. W. Allport & 197 & 6. C. Hull & 285 \\
7. J. Piaget & 192 & 7. E. L. Thorndike & 214 \\
8. E. G. Boring & 152 & 8. E. C. Tolman & 129 \\
9. K. Spence & 138 & 9. B. F. Skinner & 122 \\
10. J. S. Bruner & 136 & 10. A. Binet & 117 \\
Total Names Listed & 132 & Total Names Listed & 88 \\
\hline
\end{tabular}

Note-W. K. Estes and L. Festinger would be added to the list of contemporary psychologists on the basis of total number of votes; $W$. Kohler would be added to the list of all-time psychologists on the basis of total number of votes. Mailing sample: Psychology department chairpersons $(n=89)$ listed by Ross and Harmon (1966).

with those of the faculty providing their instruction? The present project sought to provide tentative answers to such questions.

The initial phase essentially replicated the 1966 survey. A letter briefly outlining the project and requesting cooperation in listing the 10 most important contemporary psychologists and the 10 most important psychologists from any time period was sent to each member of the Council of Graduate Departments of Psychology. Although this was not exactly the same source of respondents (Ross \& Harmon, 1966) employed in the previous survey, it was deemed similar enough to allow comparisons. As with the earlier survey, weighted ranks (i.e., 10 for psychologists ranked first, 9 for those ranked second, etc.) were assigned to the responses. The results of this survey are shown in Table 2.

Comparison of Tables 1 and 2 reveals several interesting trends. The most readily apparent finding was that 
Table 2

Most Important Contemporary and All-Time Psychologists According to Graduate Psychology Department Chairpersons-1981

\begin{tabular}{lrllc}
\hline Contemporary & Points & & All Time & Points \\
\hline 1. B. F. Skinner & 622 & 1. S. Freud & 469 \\
2. C. R. Rogers & 295 & 2. B. F. Skinner & 355 \\
3. N. Miller & 233 & 3. J. Piaget & 254 \\
4. D. O. Hebb & 155 & 4. I. Pavlov & 210 \\
5. A. Bandura & 154 & 5. W. James & 202 \\
6. E. Hilgard & 84 & J. B. Watson & 202 \\
7. L. Cronbach & 78 & 7. C. Hull & 173 \\
8. H. F. Harlow & 77 & W. Wundt & 173 \\
9. E. Erikson & 72 & 9. E. L. Thorndike & 157 \\
10. L. Festinger & 68 & 10. C. R. Rogers & 92 \\
Total Names Listed & 153 & Total Names Listed & 105 \\
\hline
\end{tabular}

Note-H. Eysenck and W. Estes would be added to the list of contemporary psychologists on the basis of total number of votes; E. C. Tolman would be added to the list of all-time psychologists on the basis of total number of votes. Mailing sample: Members of the Council of Graduate Departments of Psychology $(n=72)$.

several of the persons listed in 1966 were also listed, with identical rankings, in 1981. For example, B. F. Skinner, Carl Rogers, and Neal Miller were listed, in that order, as the three most important contemporary psychologists. H. F. Harlow and D. O. Hebb round out the five psychologists who were common to the two contemporary lists. Similarly, eight persons were mentioned on both all-time lists: Freud, James, Wundt, Pavlov, Hull, Watson, Thorndike, and Skinner. Despite several deaths (e.g., Boring, Piaget, Spence), only Piaget was able to make the transition from the 1966 contemporary to the 1981 all-time list. His ranking of third in 1981 would not appear to be a chance happening. The only other psychologist to be added to the 1981 all-time list was Carl Rogers. It is also interesting, and perhaps important, to note that a larger number of different names was proposed by the 1981 respondents than by the 1966 respondents. More specifically, the 89 respondents to the 1966 survey listed 132 contemporary and 88 all-time persons, whereas the 72 respondents to the 1981 survey listed 153 contemporary and 105 all-time candidates. This increase in numbers would seem to suggest that psychology has, indeed, become more specialized and/or compartmentalized.

To examine the relationship between responses on the national survey and those from a single institution, the second portion of the study asked all Emporia State University psychology faculty and graduate teaching assistants to complete the same instrument as was used in the national survey. The same weighted-ranks scoring procedure was used to evaluate these responses. The complete faculty and teaching assistant preferences are shown in Table 3. A comparison of Tables 2 and 3 reveals remarkable similarities between the all-time lists. All of the names listed by the national sample were also listed by the departmental faculty. Likewise, with the exception of Carl Rogers, the teaching assistants' responses coincided with the national all-time list. A more detailed inspection of these tables indicates that some variations in rank ordering were present. The most noticeable variation would appear to be the ranks afforded B. F. Skinner and Sigmund Freud by the teaching assistants.

A consideration of the contemporary portion of Tables 2 and 3 yields a somewhat more complicated picture. Only five names (Skinner, Rogers, Hebb, Bandura, and Miller) are common to all three lists. Of these, only B. F. Skinner retained the same ranking, first, on all three lists. However, given that only five names were common to the contemporary portions of the 1966 and 1981 national surveys, this complexity may simply reflect a state of change regarding those contemporary psychologists who are viewed as prominent or important. Further, the listing of Frank Beach, an Emporia State alumnus, on both contemporary lists in Table 3 would appear to be reflective of the role that specific institutional ties and/or regional biases may play in the perception of importance.

The final phase of the study sought to determine the degree of correspondence that exists between the responses of those providing instruction (i.e., faculty and teaching assistants) and the responses of their students. All students enrolled in psychology courses at Emporia State University during the semester in which the national and faculty surveys were administered were asked to respond to the following questions: "Who is

Table 3

Most Important Contemporary and All-Time Psychologists According to Emporia State University Faculty and Graduate Teaching Assistants-1981

\begin{tabular}{|c|c|c|c|}
\hline Contemporary & Points & All Time & Points \\
\hline \multicolumn{4}{|c|}{ Faculty $(n=11)$} \\
\hline 1. B. F. Skinner & 109 & 1. S. Freud & 80 \\
\hline 2. C. Rogers & 51 & 2. B. F. Skinner & 71 \\
\hline 3. H. Harlow & 34 & 3. J. B. Watson & 68 \\
\hline 4. A. Bandura & 33 & 4. J. Piaget & 49 \\
\hline D. O. Hebb & 33 & 5. W. Wundt & 48 \\
\hline 6. J. Bruner & 22 & 6. I. Pavlov & 41 \\
\hline 7. N. Miller & 20 & E. L. Thorndike & 41 \\
\hline 8. F. Beach & 16 & 8. W. James & 28 \\
\hline A. Amsel & 16 & 9. C. Hull & 21 \\
\hline 10. J. Kagan & 15 & 10. C. Rogers & 16 \\
\hline \multicolumn{4}{|c|}{ Graduate Teaching Assistants $(n=7)$} \\
\hline 1. B. F. Skinner & 66 & 1. B. F. Skinner & 43 \\
\hline 2. A. Bandura & 33 & 2. I. Pavlov & 41 \\
\hline 3. D. O. Hebb & 32 & 3. W. Wundt & 38 \\
\hline 4. C. Rogers & 25 & 4. S. Freud & 35 \\
\hline 5. A. Amsel & 21 & 5. C. Hull & 26 \\
\hline 6. J. Piaget & 18 & J. B. Watson & 26 \\
\hline \multirow{2}{*}{$\begin{array}{l}\text { 7. N. Miller } \\
\text { J. Wolpe }\end{array}$} & 12 & J. Piaget & 26 \\
\hline & 12 & 8. W. James & 25 \\
\hline 9. F. Beach & 9 & 9. E. L. Thorndike & 24 \\
\hline 10. D. Premack & 9 & 10. A. Binet & 11 \\
\hline
\end{tabular}


the most important contemporary (living) psychologist?" and "Who is the most important psychologist of all time?" Students were also asked to indicate their gender and course number on the questionnaire. All questionnaires were completed in a regular class session during the 12th week of the semester. To avoid duplications, students were requested not to repeat the questionnaire if they had completed it in another class.
Responses were tallied by gender and course level (freshman, sophomore, junior, and senior-graduate). The 10 most popular responses (determined by frequency) for each category are shown in Table 4 . It is interesting, although perhaps not surprising, to note that, regardless of sex, Sigmund Freud was unanimously listed as the most important psychologist of all time. Similarly, it can be argued that B. F. Skinner was regarded as the

Table 4

Most Important Contemporary and All-Time Psychologists According to Emporia State University Students-1981

\begin{tabular}{|c|c|c|c|c|c|c|c|}
\hline \multicolumn{4}{|c|}{ Male Students } & \multicolumn{4}{|c|}{ Female Students } \\
\hline Contemporary & Votes & All Time & Votes & Contemporary & Votes & All Time & Votes \\
\hline \multicolumn{8}{|c|}{ Freshman Students } \\
\hline 1. B. F. Skinner & 26 & 1. S. Freud & 97 & 1. None Listed & 51 & 1. S. Freud & 127 \\
\hline 2. None Listed & 19 & 2. None Listed & 5 & 2. B. F. Skinner & 34 & 2. B. F. Skinner & 12 \\
\hline 3. Class Instructor & 17 & 3. A. Maslow & 3 & 3. C. Rogers & 16 & 3. A. Maslow & 11 \\
\hline 4. C. Rogers & 8 & 4. J. Piaget & 3 & 4. J. Brothers & 15 & 4. E. Erikson & 10 \\
\hline 5. J. Piaget & 6 & B. F. Skinner & 3 & 5. J. Piaget & 12 & 5. J. B. Watson & 4 \\
\hline 6. A. Maslow & 5 & J. B. Watson & 3 & 6. K. Menninger & 8 & 6. I. Pavlov & 3 \\
\hline Text Author & 5 & 7. C. Jung & 2 & Class Instructor & 8 & None Listed & 3 \\
\hline 8. H. Harlow & 4 & C. Rogers & 2 & 8. A. Bandura & 6 & 8. C. Darwin & 2 \\
\hline 9. J. Brothers & 3 & 9. E. Erikson & 1 & 9. E. Erikson & 5 & J. Piaget & 2 \\
\hline E. Erikson & 3 & I. Pavlov & 1 & H. Harlow & 5 & C. Rogers & 2 \\
\hline ESU Faculty & 3 & W. Wundt & 1 & A. Maslow & 5 & E. L. Thorndike & 2 \\
\hline$(n=122)$ & & $(n=122)$ & & $(n=182)$ & & $(n=182)$ & \\
\hline \multicolumn{8}{|c|}{ Sophomore Students } \\
\hline 1. B. F. Skinner & 14 & 1. S. Freud & 27 & 1. None Listed & 33 & 1. S. Freud & 78 \\
\hline 2. E. Erikson & 3 & 2. J. Piaget & 5 & 2. B. F. Skinner & 29 & 2. J. Piaget & 66 \\
\hline K. Menninger & 3 & 3. B. F. Skinner & 2 & 3. E. Erikson & 25 & 3. B. F. Skinner & 10 \\
\hline None Listed & 3 & 4. E. Berne & 1 & 4. K. Menninger & 13 & 4. I. Pavlov & 3 \\
\hline 5. J. Brothers & 2 & C. Jung & 1 & 5. C. Rogers & 9 & 5. A. Adler & 2 \\
\hline F. Perls & 2 & J. B. Watson & 1 & 6. J. Brothers & 8 & C. Darwin & 2 \\
\hline Class Instructor & 2 & None Listed & 1 & J. Piaget & 8 & E. Erikson & 2 \\
\hline$(n=38)^{*}$ & & $(n=38)$ & & 8. M. Banks & 6 & C. Jung & 2 \\
\hline & & & & 9. A. Maslow & 4 & J. B. Watson & 2 \\
\hline & & & & Class Instructor & 4 & None Listed & 2 \\
\hline & & & & $(n=173)$ & & $(n=173)$ & \\
\hline \multicolumn{8}{|c|}{ Junior Students } \\
\hline 1. B. F. Skinner & 50 & 1. S. Freud & 38 & 1. B. F. Skinner & 95 & 1. S. Freud & 75 \\
\hline 2. K. Menninger & 6 & 2. J. Piaget & 10 & 2. None Listed & 16 & 2. J. Piaget & 43 \\
\hline 3. C. Rogers & 5 & 3. J. B. Watson & 9 & 3. E. Erikson & 12 & 3. J. B. Watson & 9 \\
\hline 4. J. Bruner & 3 & 4. B. F. Skinner & 7 & 4. K. Menninger & 11 & 4. B. F. Skinner & 8 \\
\hline 5. A. Bandura & 2 & 5. I. Pavlov & 3 & 5. J. Bruner & 7 & 5. A. Binet & 6 \\
\hline$(\mathrm{n}=84) * *$ & & 6. W. James & 2 & 6. J. Piaget & 6 & 6. K. Menninger & 5 \\
\hline & & C. Rogers & 2 & C. Rogers & 6 & 7. None Listed & 4 \\
\hline & & T. Szasz & 2 & 8. A. Anastasi & 4 & 8. W. James & 3 \\
\hline & & W. Wundt & 2 & 9. J. Brothers & 2 & C. Jung & 3 \\
\hline & & $(n=84)$ & & $\begin{array}{l}\text { Class Instructor } \\
(n=172)\end{array}$ & 2 & $\begin{array}{l}\text { I. Pavlov } \\
(n=172)\end{array}$ & 3 \\
\hline \multicolumn{8}{|c|}{ Senior and Graduate Students } \\
\hline 1. B. F. Skinner & 17 & 1. S. Freud & 10 & 1. B. F. Skinner & 17 & 1. S. Freud & 10 \\
\hline 2. C. Rogers & 4 & 2. J. B. Watson & 4 & 2. C. Rogers & 8 & J. Piaget & 10 \\
\hline 3. G. Bower & 1 & J. Piaget & 4 & 3. None Listed & 4 & 3. C. Jung & 2 \\
\hline M. Gazzaniga & 1 & 4. C. Beers & 1 & 4. C. Jung & 2 & 4. I. Pavlov & 2 \\
\hline A. Maslow & 1 & C. Hull & 1 & W. Glasser & 2 & B. F. Skinner & 2 \\
\hline None Listed & 1 & A. Maslow & 1 & $(n=41) \dagger$ & & $(n=41) \dagger \dagger$ & \\
\hline$(n=25)$ & & I. Pavlov & 1 & & & & \\
\hline & & C. Rogers & 1 & & & & \\
\hline & & B. F. Skinner & 1 & & & & \\
\hline & & W. Wundt & 1 & & & & \\
\hline & & $(n=25)$ & & & & & \\
\hline
\end{tabular}

*Nine others received one vote each. $\quad$ **Seventeen others received one vote each; one student had none listed. $\quad$ tEight others received one vote each. ttEleven others received one vote each. 
most important contemporary psychologist. However, this conclusion must be qualified by indicating that the most frequent response among freshman and sophomore females in the contemporary category was no response at all. Likewise, Table 4 also indicates that males in freshman and sophomore courses and junior-level females also showed a tendency (albeit, not as pronounced) to not list a contemporary psychologist. It should be noted that all questionnaires $(n=6)$ failing to list a name in at least one of the categories were not included in these tabulations. As one progresses through the courses from freshman to senior-graduate levels, it can be seen that the frequency of the "none listed" response decreases. Rather than offer prescriptive advice regarding this trend, we would simply suggest that this may reflect the students' perceptions of psychology in these lower level couses. Concentration on facts and terminology would appear to have been accomplished at the expense of considering contemporary "great men." Judging from Table 4, such considerations would seem to be provided in the upper division and graduate-level courses.

Three further trends in the students' data seem worthy of elaboration. First, students in the lower division classes listed a number of tangential, "popular" psychologists, such as Joyce Brothers and Murray Banks. Second, Table 4 also reveals a degree of regionality. For example, Karl Menninger, a prominent Topeka, Kansas, psychiatrist, was consistently listed among the most important contemporary psychologists. Likewise, class instructors and other Emporia State faculty received frequent nominations. (As instructors, we may overlook how great our impact is upon our students.) Finally, as already suggested, it would appear that the responses offered by the students became more sophisticated and/ or critical as one proceeds from lower level (freshman and sophomore) courses to upper level (junior, seniorgraduate) courses.
The results obtained from all three phases of the present study would appear to support the contention that the number of names recognizable across all aspects of the field may be on the decline. However, this does not mean that psychology, as a profession, is without "greats." We now seem quite ready to consider those prominent figures within our respective specialty areas as having achieved the status of importance. It will be interesting to see how well these prominent figures stand the test of time. Will they be able to achieve a place of lasting importance? If so, which of those currently listed as having achieved all-time importance will they replace?

\section{REFERENCE NOTE}

1. Moore, M. H., \& Seberhagen, L. W. Personal communication, August 18, 1967.

\section{REFERENCES}

Hull, C. L. Principles of behavior. New York: Appleton, 1943. Hull, C. L. A behavior system. New Haven, Conn: Yale University Press, 1952.

LeAhey, T. L. A history of psychology. Englewood Cliff, N. J: Prentice-Hall, 1980.

Ross, S., \& Harmon, J. Educational facilities and financial assistance for graduate students in psychology: 1966-1967. American Psychologist, 1966, 21, 52-77.

Sahakian, W. S. History of psychology: A source book in systematic psychology (Rev. ed.). Itasca, Ill: Peacock, 1981.

Schultz, D. A history of modern psychology (2nd ed.). New York: Academic Press, 1975.

Schultz, D. A history of modern psychology (3rd ed.). New York: Academic Press, 1981.

SPEnCE, K. W. Behavior theory and learning: Selected papers. Englewood Cliffs, N.J: Prentice-Hall, 1960.

Tolman, E. C. Purposive behavior in animals and men. New York: Appleton, 1932.

Thorndike, E. L. Human learning. New York: Appleton, 1931.

(Received for publication April 5, 1982.) 